\title{
MENINGKATKAN KEMAMPUAN KOMUNIKASI MATEMATIS DAN SELF EFFICACY SISWA SMP MENGGUNAKAN PENDEKATAN REALISTIC MATHEMATICS EDUCATION
}

\author{
Rehan Wulandari ${ }^{1}$, Julfah Rodiyah Kusumawati. ${ }^{2}$, Gida Kadarisma ${ }^{3}$ \\ 1,2,3 ${ }^{1}$ IKIP Siliwangi, Jl. Jend. Sudirman Cimahi \\ 1rhnwulandari@gmail.com, ${ }^{2}$ julfahrodiyah@gmail.com, ${ }^{3}$ gidakadarisma@ikipsiliwangi.ac.id
}

\begin{abstract}
This study aims to analyze how the ability of mathematical communication and Self Efficacy by using Realistic Mathematics Education (RME) approach in junior high school students. The research method used is quasi-experimental using two classes, first class as experiment class and second class as control class. The experimental class uses the Realistic Mathematics Education (RME) approach while the control class uses conventional learning. In both classes, pretest and initial questionnaire were conducted to determine the initial ability of each class, and at the end of the two classes postest. The results of this study were processed and analyzed using Mann-Whitney test. The results showed that communication skills and self-efficacy of students whose learning using Realistic Mathematics education are better than those using conventional learning.
\end{abstract}

Kata Kunci: Mathematical Communication Ability, Self-Efficacy, Realistic Mathematics Education.

\begin{abstract}
Abstrak
Penelitian ini bertujuan untuk menganalisis bagaimana kemampuan komunikasi matematis dan Self Efficacy dengan menggunakan pendekatan Realistic Mathematics Education (RME) pada siswa SMP. Metode penelitian yang digunakan adalah metode kuasi eksperimen dengan menggunakan dua kelas, kelas pertama sebagai kelas eksperimen dan kelas kedua sebagai kelas kontrol. Kelas eksperimen menggunakan pendekatan Realistic Mathematics Education (RME) sedangkan kelas kontrol yang menggunakan pembelajaran biasa. Pada kedua kelas dilakukan pretes serta angket awal untuk mengetahui kemampuan awal pada masing-masing kelas, dan pada akhir kedua kelas dilakukan postes. Hasil dari penelitian ini diolah dan di analisis menggunakan uji Mann-Whitney. Hasil penelitian menunjukkan bahwa kemampuan komunikasi dan self-efficacy siswa yang pembelajarannya menggunakan Realistic Mathematic education lebih baik daripada yang menggunakan pembelajaran biasa.
\end{abstract}

Kata Kunci: Kemampuan Komunikasi Matematis, Self-Efficacy, Realistic Mathematics Edcucation.

How to cite: Wulandari, R., Kusumawati, J. R., \& Kadarisma, G. (2018). Meningkatkan Kemampuan Komunikasi Matematis dan Self Efficacy Siswa SMP Menggunakan Pendekatan Realistic Mathematics Education. JPMI - Jurnal Pembelajaran Matematika Inovatif, 1 (4), 679-686.

\section{PENDAHULUAN}

Matematika merupakan mata pelajaran yang penting untuk dipelajari mengingat jasanya yang begitu besar dalam kemajuan IPTEK saat ini, namun menurut studi siswa banyak yang ingin menghindari mata pelajaran ini karena dianggap cukup sulit (Hidayat, 2012) .Untuk menguasai pelajaran matematika bukan hanya rumus yang harus dikuasai oleh siswa. Barody 
mengungkapkan bahwa dalam menguasai matematika siswa harus menguasai kemampuankemampuan seperti membaca, menulis menyimak, menelaah, meninterpretasi, dan mengevaluasi suatu ide, symbol, dan istilah serta informasi matematika (Hasanah, Rochmad, \& I.Hidayah, 2012). Apa yang dikemukakan Barody tersebut adalah beberapa unsur-unsur yang tercakup ke dalam kemampuan komunikasi matematis, itu berarti kemampuan komunikasi matematis sangat penting dipelajari dan dikuasai oleh siswa. Hal ini sesuai dengan apa yang dikemukakan Barody bahwa kemampuan komunikasi matematis penting untuk dipelajari disekolah adalah karena matematika bukan sekedar alat bantu berpikir siswa, alat untuk menemukan pola, menyelesaikan masalah atau mengambil keputusan, tetapi matematika juga sebagai alat untuk mengkomunikasikan berbagai ide dengan jelas, tepat dan ringkas. Selain itu kemampuan komunikasi matematika adalah sebagai aktivitas social dalam pembelajaran di sekolah, matematika juga sebagai alat interaksi antar siswa dan juga sebagai sarana komunikasi guru dan siswa (Wahyuni, Utami, \& Husna, 2016). Kemampuan komunikasi matematis terbagi kedalam dua kemampuan dalam menyampaikan ide matematika, yaitu kemampuan komunikasi matematis secara lisan dan secara tulisan. Kemampuan komunikasi matematis secara lisan dapat dinilai saat siswa mengemukakan pendapat atau menyampaikannya dalam sebuah wacana. Kemampuan komunikasi matematis secara tertulis dapat dinilai saat siswa mengerjakan seperangkat soal tentang kemampuan komunikasi matematis (Hidayat, \& Sumarmo, 2013; Rahmi, Nadia, Hasibah, \& Hidayat, 2017; Zakiah, Saomi, Syara, Hidayat, \& Hendriana, 2018).

Kemampuan komunikasi matematis yaitu: 1) Siswa mampu menyatakan ke dalam sebuah symbol, ide, bahasa dan model matematika suatu benda nyata, gambar, situasi, dan diagram; 2) Siswa mampu menjelaskan sebuah ide matematika, situasi dan relasi secara lisan dan tulisan; 3) Siswa mampu mendengarkan, berdiskusi dan menulis sebuah ide matematika; 4) Siswa mampu membaca suatu representasi matematika tertulis dengan pemahaman; 5) Siswa mampu membuat konjetur, menyusun argument, merumuskan definisi, mengeneralisasi, dan siswa mampu mengungkapkan kembali suatu uraian atau paragraf matematika dalam bahasanya sendiri (Putra \& Sibarani, 2015)

Untuk menghasilkan siswa yang menguasai kemampuan komunikasi matematis, maka diperlukannya kerja sama antara siswa dan guru untuk mencapai tujuan tersebut. Guru memerankan peranan yang penting dalam menghasilkan siswa yang menguasai kemampuan komunikasi matematis. Siwa seringkali merasa kesulitan dalam memahami materi dikarenakan siswa hanya menghafal rumus dan pembelajaran yang dibawakan oleh guru masih prosedural (Putri, Nursyahban, Kadarisma, \& Rohaeti, 2018). Untuk membentuk siswa tersebut guru harus berinovasi agar kemampuan komunikasi matematis tersebut terbentuk. Salah satu inovasi yang dapat digunakan adalah dalam menentukan pendekatan pembelajaran yang digunakan. Dalam pembelajaran matematika guru tidak selayaknya hanya memberikan simbol-simbol abstrak dan teorema yang membosankan bagi sebagian besar siswa, karena melalui penyampaian tujuan pembelajaran yang jelas dan pendekatan realistis, matematika akan menjadi teman keseharian siswa (Sariningsih \& Kadarisma, 2017). Pendekatan Realistic Mathematics Education (RME) adalah pendekatan yang cocok untuk mengembangkan kemampuan komunikasi matematis siswa. Pendekatan Realistic Mathematics Education (RME) adalah pendekatan yang berorientasi kepada pengalaman sehari-sehari siswa. Menurut Zulkardi, pada pendekatan RME peranan guru adalah sebagai fasilitator, moderator atau evaluator, sementara siswa dituntut untuk berpikir, mengkomunikasikan penalarannya, dan melatih siswa untuk menghargai pendapat orang lain. Selain itu, pendekatan Realistic Mathematics Education (RME) salah satu pendekatan yang sejalan dengan paham konstruktivisme. Realistic Mathematics Education (RME) menekankan keterampilan dalam 
proses mengerjakan matematika, berdiskusi dan bekerjasama dengan teman sekelas sampai mereka dapat menemukan sendiiri dan dapat menggunakannya sebgai alat untuk menyelesaikan masalah baik secara individu maupun kelompok (Anasrudin, Misu, \& Nadia, 2014).

Selain menumbuhkan dan meningkatkan kemampuan kognitif dalam hal ini kemampuan komunikasi matematis, perlu juga dikembangkan dan ditingkatkan kemampuan afektif siswa. Hal ini sesuai dengan Peraturan Menteri Pendidikan Nasional (Permendiknas) Nomor 22 Tahun 2006 tentang Standar Isi yang salah satu poin nya menyatakan bahwa siswa harus memiliki sikap menghargai kegunaan matematika dalam kehidupan yaitu memiliki rasa ingin tahu, perhatian, dan minat dalam mempelajari matematika, serta sikap ulet dan percaya diri dalam pemecahan masalah. Self Efficacy adalah salah satu kemampuan afektif yang sejalan dengan maksud dan tujuan permendiknas tersebut. Bandura menyampaikan pengertian Self Efficacy adalah keyakinan seseorang terhadap kemampuannya dalam mengatur dan melaksanakan serangkian tindakan untuk mencapai hasil yang ditetapkan (Hendriana, Rohaeti, \& Sumarmo, 2017). Menurut penelitian sebelumnya, terdapat hubungan yang signifikan antara Self Efficacy dan kemampuan komunikasi matematik siswa (Rahmi, Nadia, Hasibah, \& Hidayat, 2017). Oleh karena itu, kemampuan Self Efficacy perlu ditingkatkan dalam diri peserta didik agar dapat memaknai jalannya pembelajaran matematika dalam kehidupan konkret, serta siswa dapat menentukan target dalam belajar agar tujuan pembelajaran dapat tercapai sehingga jalannya pembelajaran berlangsung secara maksimal (Kadarisma, 2017). Dari pemaparan tersebut peneliti ingin mengetahui apakah dengan RME kemampuan komunikasi dan self efficacy dapat ditingkatkan.

\section{METODE}

Metode penelitian yang digunakan dalam penelitian ini adalah metode eksperimen semu atau kuasi eksperimen. Menurut Sandjaya dan Albertus kuasi eksperimen yaitu metode yang tidak memungkinkan peneliti melakukan pengontrolan penuh terhadap variable dan kondisi eksperimen. Adapun jenis penelitian yaitu kuantitatif dengan desain penelitian pre-test posttest control grup design (Fitrina, Ikhsan, \& Munzir, 2016). Dalam penelitian ini terdapat dua variabel bebas yaitu pendekatan pembelajaran yaitu pendekatan Realistic Mathematics Education (RME) dan kemampuan komunikasi matematis siswa, dan satu variabel terikat yaitu Self Efficacy matematis siswa. Subyek dalam penelitian ini adalah siswa kelas VIII di SMP Swasta di Kota Bandung, dengan 1 kelas dijadikan kelas eksperimen yaitu kelas yang menerima pembelajaran dengan pendekatan Realistic Mathematics Education (RME), dan 1 kelas kontrol yaitu kelas yang menerima pembelajaran seperti biasa.

Instrumen yang digunakan dalam penelitian ini ada 2 yaitu instrumen tes kemampuan komunikasi matematis berupa seperangkat soal essay, dan instrument angket untuk mengukur Self Efficacy siswa.

\section{HASIL DAN PEMBAHASAN}

\section{Hasil}

Kemampuan komunikasi matematis siswa setelah mengalami pembelajaran dengan pendekatan Realistic Mathematics Education (RME) pada kelas eksperimen dan pembelajaran biasa pada kelas kontrol terlihat pada table di bawah ini: 
Tabel 1. Kemampuan komunikasi matematis kelas eksperimen dan kelas kontrol

\begin{tabular}{ccc}
\hline \multirow{2}{*}{ Statistik Deskriptif } & \multicolumn{2}{c}{ Kelompok } \\
\cline { 2 - 3 } & Eksperimen & Kontrol \\
\hline Jumlah Siswa & 30 & 30 \\
Nilai Maksimum & 31 & 26 \\
Nilai Minimum & 20 & 14 \\
Nilai rata-rata & 25,50 & 20,20 \\
Median & 25 & 20 \\
Varian & 10,810 & 9,683 \\
Simpangan Baku & 3,288 & 3,112 \\
Kemiringan & 0,103 & 0,418 \\
Ketajaman & $-0,933$ & $-0,236$ \\
\hline
\end{tabular}

Dari Table 1 tersebut perbandingan kemampuan komunikasi matematis siswa antara kelas eksperimen dan kelas kontrol, dapat terlihat perolehan nilai rata-rata siswa kelas eksperimen lebih tinggi daripada nilai rata-rata kelas kontrol dengan selisih 5,30. Begitu juga dengan median pada kelas eksperimen diperoleh 25, sedangkan pada kelas kontrol diperoleh 20 . Standar deviasi atau simpangan baku kelas eksperimen dan kelas kontrol berturut-turut diperoleh 3,288 dan 3,112. Sedangkan varians pada kelas eksperimen dan kelas kontrol berturut-turut diperoleh 10,810 dan 9,683. Berdasarkan pada hal tersebut, dapat disimpulkan bahwa data pada kelas kontrol lebih menyebar dibandingkan data pada kelas eksperimen. Untuk melihat perbandingan nilai minimum, nilai maksimum, dan nilai rata-rata secara signifikan dapat kita lihat pada Gambar 1 dibawah ini:

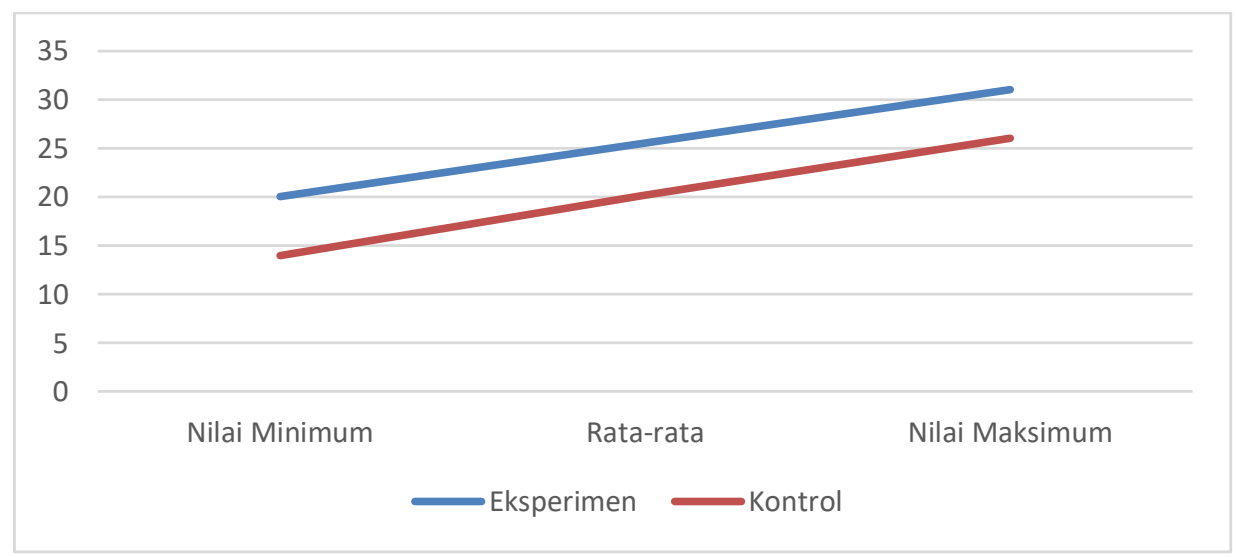

Gambar 1. Perbandingan kemampuan komunikasi matematis nilai kelas eksperimen dan nilai kelas kontrol

Dari Gambar 1 dapat kita lihat bahwa nilai pada kelas eksperimen lebih baik dibanding nilai kelas kontrol. Hal tersebut terlihat dari nilai eksperimen yang berada diatas nilai kontrol.

\section{Pembahasan}

Pada penelitian ini instrumen soal kemampuan komunikasi matematis terdiri dari 5 soal dengan 4 indikator kemampuan komunikasi matematis, yaitu 1) Menyatakan peristiwa seharihari dalam bahasa dan simbol; 2) Merefleksikan benda-benda nyata, gambar dan diagram ke dalam ide atau model matematika; 3) Membuat model situasi atau masalah matematika ke 
dalam bentuk gambar, tabel, dan grafik; 4) Menjelaskan atau membuat pertanyaan/cerita tentang model matematika atau grafik atau tabel yang diberikan. Adapun angket Self Efficacy terdiri dari 27 soal dengan 7 indikator, yaitu 1) Mampu mengatasi masalah yang dihadapi; 2) Yakin akan keberhasilan dirinya; 3) Berani menghadapi tantangan; 4) Berani mengambil resiko; 5) Menyadari kekuatan dan kelemahan dirinya; 6) Mampu berinteraksi dengan orang lain; 7) Tanggung Jawab dan tidak mudah menyerah. Adapun hasil setelah siswa menerima pembelajaran dengan pendekatan Realistic Mathematics Education pada kelas eksperimen dan pembelajaran biasa pada kelas kontrol dapat dilihat dari perolehan nilai postesnya. Berikut ini grafik yang menggambarkan perbedaan kelas eksperimen dan kelas kontrol

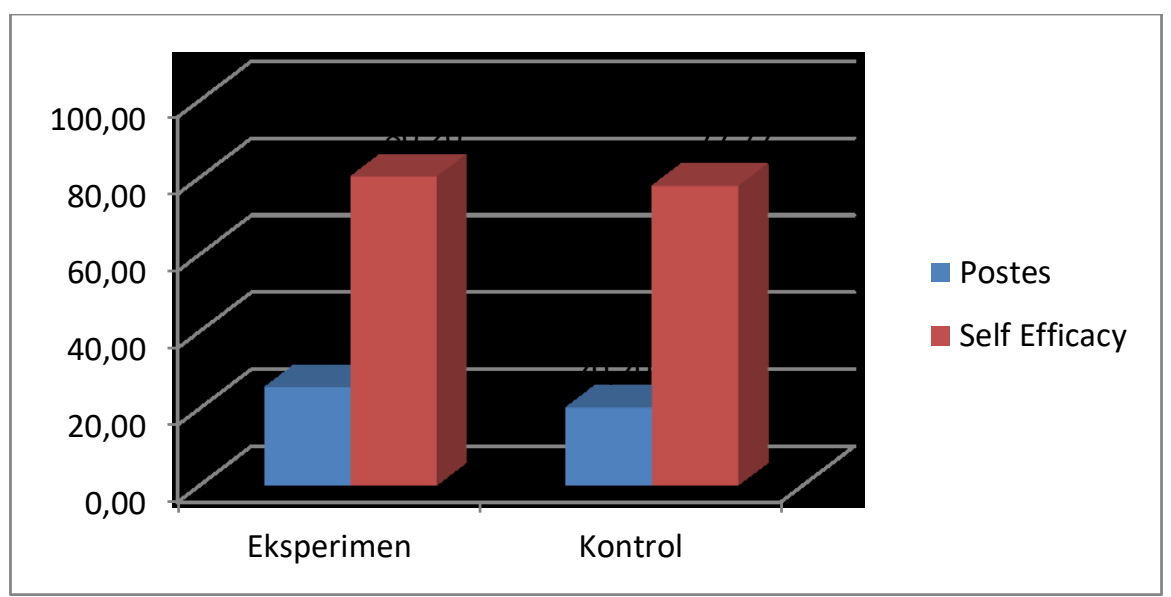

Gambar 2. Perbandimgan nilai Kemampuan Komunikasi Matematis Dan Self Efficacy Siswa Kelas Eksperimen dan kelas Kontrol

Berdasarkan gambar 2 Self Efficacy siswa kelas eksperimen yang menggunakan pendekatan pembelajaran Realistic Mathematics Education lebih tinggi dibandingkan dengan nilai postes kemampuan komunikasi dan nilai angket Self Efficacy siswa kelas kontrol yang menggunakan pembelajaran biasa. Dengan rata-rata skor postes kemampuan komunikasi kelas eksperimen adalah 25,50 dan rata-rata skor angket Self Efficacy adalah 80,20 sedangkan untuk kelas kontrol rata-rata skor postes kemampuan komunikasi matematis adalah 20,20 dan rata-rata skor angket Self Efficacy adalah 77,77.

Selanjutnya, untuk melihat apakah kemampuan komunikasi dan self eficacy siswa antara yang menggunakan RME lebih baik daripada yang menggunakan pendekatan konvensional dilakukan uji signifikansi perbedaan rata-rata, namun uji normalitas dan homogenitas perlu dilakukan. Maka untuk itu dilakukan uji normalitas kelas eksperimen dan kelas kontrol terlebih dahulu. Hasil uji normalitas ini dilakukan dengan bantuan Software SPSS 19 dan uji yang dilakukan adalah uji Kolmogorov smirnov pada taraf signifikansi $\alpha=0,05$ dan kriteria pengujian adalah $H_{0}$ diterima apabila nilai sig. $\geq \alpha$. Adapun hipotesis penelitiannya adalah sebagai berikut:

$H_{0}$ : Data kemampuan komunikasi matematis dan Self Efficacy kelas eksperimen/kontrol berdistribusi normal

$H_{1}$ : Data kemampuan komunikasi matematis dan Self Efficacy kelas eksperimen/kontrol tidak berdistribusi normal

Output dari analisis uji normalitas tersebut disajikan pada table 2 sebagai berikut: 
Tabel 2. Rangkuman Hasil Uji Normalitas Kemampuan Komunikasi Matematis dan Self Efficacy Kelas Eksperimen dan Kelas Kontrol.

\begin{tabular}{ccccccccc}
\hline \multirow{2}{*}{$\begin{array}{c}\text { Uji } \\
\text { Normalitas }\end{array}$} & Semampuan Komunikasi Matematika & \multicolumn{4}{c}{ Self Efficacy } \\
\cline { 2 - 8 } & Static & df & Sig. & $\begin{array}{c}\text { Keputusan } \\
\text { Uji }\end{array}$ & Statistic & df & Sig. & $\begin{array}{c}\text { Keputusan } \\
\text { Uji }\end{array}$ \\
\hline $\begin{array}{c}\text { Kelas } \\
\text { Eksperimen } \\
\begin{array}{c}\text { Kelas } \\
\text { Kontrol }\end{array}\end{array}$ & .110 & 30 & .005 & $H_{0}$ ditolak & .126 & 30 & .200 & $H_{0}$ diterima \\
\hline
\end{tabular}

Berdasarkan dari Tabel 2 di atas, diperoleh nilai signifikansi uji Kolmogorov Smirnov pada skor postes kemampuan komunikasi matematis yaitu 0.005 ini kurangdari 0.05 maka Ho ditolak artinya data komunikasi matematika pada kelas eksperimen tidak berdistribusi normal sedangkan pada kelas kontrol diperoleh sig 0.200 artinya data berdistribusi normal. Sedangkan Self Efficacy kelas eksperimen yaitu 0,200 > 0,05 maka $H_{0}$ diterima. Itu artinya skor angket Self Efficacy siswa yang menggunakan pendekatan pembelajaran Realistic Mathematics Education berdistribusi normal. Sedangkan untuk skor angket Self Efficacy siswa kelas kontrol diperoleh nilai signifikansi $0,042<0,05$ maka $H_{0}$ ditolak. Itu artinya data angket Self Efficacy siswa yang menggunakan pembelajaran biasa tidak berdistribusi normal. Karena pada data komunikasi dan angket salah satunya tidak berdistribusi normal, untuk uji signifikansi menggunakan uji Mann-Whitney.

pada taraf signifikansi $\alpha=0,05$, dengan hipotesis :

$$
\begin{aligned}
& \mathrm{H}_{0}: \mu_{1}=\mu_{2} \\
& \mathrm{H}_{1}: \mu_{1}>\mu_{2}
\end{aligned}
$$

Keterangan:

$\mu_{1}$ : Kemampuan komunikasi dan self-Efficacy siswa yang memperoleh model RME $\mu_{2}:$ Kemampuan komunikasi dan self-Efficacy siswa yang memperoleh pembelajaran konvensional

Kriteria pengujian, jika $p$ value (sig.) $\geq \alpha$ maka $\mathrm{H}_{0}$ diterima, dan jika $p$ value (sig.) $<\alpha$ maka tolak $\mathrm{H}_{0}$, dengan output seperti disajikan pada table 4 sebagai berikut:

Tabel 4. Hasil Uji Mann-Whitney Kemampuan Komunikasi Matematis dan Self Efficacy

\begin{tabular}{lrrr} 
& & & \multicolumn{2}{c}{ Self- } \\
& Komunikasi & & \multicolumn{1}{c}{ Efficacy } \\
\hline Mann-Whitney U & & 301.00 & 106.500 \\
Wilcoxon W & 766.00 & 569.500 \\
Z & -2.029 & -4.589 \\
Asymp. Sig. (2-tailed) & 0.027 & .000 \\
\hline
\end{tabular}

a. Grouping Variable: MODEL 
Berdasarkan hasil dari Tabel 4. diperoleh bahwa nilai sig kemampuan komunikasi dan selfefficacy berturut-turut 0.027 dan 0.00 nilai ini $<0.05$ yang artinya Ho ditolak, dengan terjadinya penolakan $\mathrm{Ho}$ maka $\mathrm{H}_{1}$ diterima,maka dapat disimpulkan bahwa kemampuan komunikasi dan self-efficacy siswa yang pembelajarannya menggunakan Realistic Mathematic education lebih baik daripada yang menggunakan pembelajaran biasa. Hal ini dikarenakan dalam belajar menggunakan RME melatih siswa aktif dan membangun pengetahuan siswa itu sendiri, belajar manjadi lebih bermakna karena dikaitkan dengan dunia nyata, sebagaimana dalam RME terdapat 5 komponen utama yaitu penggunaan konteks dunia nyata, penggunaan model, menggunakan konstruksi, aktif-interaktif, dan menggunakan keterkaitan antar topik. Sehingga kemampuan komunikasi dan self-efficacy siswa dapat meningkat.

\section{KESIMPULAN}

Kesimpulan dari hasil penelitian dan pembahasan ini adalah kemampuan komunikasi dan selfefficacy siswa yang pembelajarannya menggunakan Realistic Mathematic education lebih baik daripada yang menggunakan pembelajaran biasa

\section{DAFTAR PUSTAKA}

Anasrudin, Misu, L., \& Nadia, L. (2014). Efektivitas Pendekatan Realistic Mathematics Education (RME) terhadap Kemampuan Komunikasi Matematik Siswa Kelas VII SMP Negeri 7 Kendari. Jurnal Penelitian Pendikan Matematika, 2(2).

Fitrina, T., Ikhsan, M., \& Munzir, S. (2016). Peningkatan Kemampuan Berpikir Kreatif dan Komunikasi Matematis Siswa SMP melalui Model Pembelajaran Project Based Learning Berbasis Debat. Jurnal Didaktik Matematika, 3(1), 87-95.

Hasanah, S., Rochmad, \& I.Hidayah. (2012). Pembelajaran model reciprocal teaching bernuansa pendidikan karakter untuk meningkatkan kemampuan komuniasi matematis. Unnes Journal of Mathematics Education Research, 1(2), 134-138.

Hendriana, H., Rohaeti, E. ., \& Sumarmo, U. (2017). Hard Skills dan Soft Skills Matematik Siswa. Bandung: PT. Refika Aditama.

Hidayat, W. (2012). Meningkatkan Kemampuan Berpikir Kritis dan Kreatif Matematik Siswa SMA Melalui Pembelajaran Kooperatif Think-Talk-Write (TTW). Prosiding Seminar Nasional Penelitian, Pendidikan dan Penerapan MIPA.

Hidayat, W., \& Sumarmo, U. (2013). Kemampuan Komunikasi dan Berpikir Logis Matematika serta Kemandirian Belajar. dalam Jurnal Delta-fi, 2(1).

Kadarisma, G. (2017). Meningkatkan Kemandirian Belajar Siswa SMP dalam Matematika dengan Menggunakan Pendekatan Saintifik. Symmetry: Pasundan Journal of Research in Mathematics Learning and Education, 1(1), 61-66.

Putra, J. D., \& Sibarani, P. A. (2015). Penerapan Pendekatan Realistic Mathematic Education (RME) Berbasis LKS dalam Meningkatkan Kemampuan Komunikasi Matematis Siswa 
Kelas VIII SMP Baptis Batam Tahun Pelajaran 2013/2014, 4(1), 28-38.

Putri, N. R., Nursyahban, E. A., Kadarisma, G., \& Rohaeti, E. E. (2018). ANALISIS KEMAMPUAN PEMAHAMAN MATEMATIK SISWA SMP PADA MATERI SEGITIGA DAN SEGIEMPAT. JPMI (Jurnal Pembelajaran Matematika Inovatif), 1(2), 157-170.

Rahmi, S., Nadia, R., Hasibah, B., \& Hidayat, W. (2017). The Relation between Self-Efficacy toward Math with the Math Communication Competence. Infinity Journal, 6(2), 177 182.

Sariningsih, R., \& Kadarisma, G. (2017). Meningkatkan Kemampuan Berpikir Kreatif Matematis dan Kemandirian Belajar Siswa SMP Melalui Pendekatan Saintifik berbasis Etnomatematika. P2M STKIP Siliwangi, 3(1), 53-56.

Wahyuni, R., Utami, C., \& Husna, N. (2016). Pengaruh Model Role Playing Terhadap Kemampuan Komunikasi Matematis Siswa Pada Materi Fungsi Komposisi Kelas XI Sma Negeri 6 Singkawang. Jurnal Pendidikan Matematika Indonesia, 1(2), 81-86.

Zakiah, L., Saomi, A. S. N., Syara, R., Hidayat, W., \& Hendriana, H. (2018). THE EFFICIENCY OF USING EDUCATION VIDEOS ON THE LINEAR PROGRAM MATERIAL AS OBSERVED IN VOCATIONAL HIGH SCHOOL STUDENTS'MATHEMATICAL COMMUNICATION ABILITY. Journal of Educational Experts (JEE), 1(1), 11-18. 